\title{
Regulation mechanism of exogenous ALA on growth and physiology of Leymus chinensis (Trin.) under salt stress
}

\author{
Shakeel Ahmad Anjum ${ }^{1}$, Jin-huan $\mathrm{Li}^{1}$, Jun Lv ${ }^{1}$, Xue-feng Zong ${ }^{1}$, Ling Wang ${ }^{1}$, \\ Ai-jie Yang ${ }^{1}$, Rong Yan ${ }^{1}$, Zohaib Ali $^{2}$, Ji-xuan Song ${ }^{1}$, and San-gen Wang ${ }^{1 *}$
}

\section{ABSTRACT}

Salt stress is one of major problem hampering plant growth and development to a significant level. In present study, 5-aminolevulinic acid (ALA) was exogenously applied to Leymus chinensis (Trin.) Tzvel. plants at various concentrations $\left(10,50\right.$, and $\left.100 \mathrm{mg} \mathrm{L}^{-1}\right)$ to assess its effects on morphology, physiology, and biochemistry under salt stress conditions (150 mmol NaCl L-1) as compared with control. The results indicated that salt stress substantially impaired growth, physiology and biochemistry of L. chinensis plants; nonetheless, ALA application alleviated the adverse effects of salt stress. Application of ALA improved the leaf length, leaf area, leaf conductance, plant dry biomass, water contents, and root activity of L. chinensis under stress and no stress conditions. Additionally, biosynthesis of chlorophyll, carotenoids, free proline, soluble sugars and proteins of $L$. chinensis plants was also increased following ALA application as compared to control, under salt stress conditions. Moreover, we also observed an enhanced activity of antioxidant defense system in L. chinensis in response to ALA application. ALA elevated the activity of enzymatic antioxidants viz. ascorbate peroxidase (APX), glutathione reductase (GR), superoxide dismutase (SOD), catalase (CAT) and peroxidase (POD) significantly scavenged reactive oxygen species thus reduced the accumulation of malondialdehyde (MDA) under salt stress as compared to control under both normal and stressed conditions. The effect of ALA on all growth and biochemical attributes was concentration dependent and application of 50 as well as $100 \mathrm{mg} \mathrm{L}^{-1}$ ALA proved better. The results concluded that salt stress tolerance in L. chinensis plants can be increased by exogenously applied ALA at appropriate concentration. It was suggested that L. chinensis plants were treated with ALA application of $50-100 \mathrm{mg} \mathrm{L}^{-1}$ was more beneficial under both normal and saline conditions.

Key words: 5-Aminolevulinic acid (ALA), antioxidant enzymes, growth, Leymus chinensis, salt stress.

${ }^{1}$ Southwest University, College of Agronomy and Biotechnology, Engineering Research Center of South Upland Agriculture, Chongqing 400716, China. "Corresponding author (wangsg@swu.edu.cn).

${ }^{2}$ University of Agriculture, Department of Agronomy, Faisalabad 38040, Pakistan.

Received: 17 February 2016.

Accepted: 1 July 2016.

doi:10.4067/S0718-58392016000300008

\section{INTRODUCTION}

The grasslands of China are widely and Leymus chinensis (Trin.) Tzvel. (sheep grass) is a dominant grass in the grasslands of China having high forage quality, productivity, palatability and nutritious value with high carbohydrate, protein and mineral content (Wang et al., 2009). During the last decade, it has been noticed that the grasslands of China are being undermined owing to the over grazing, land degradation, over land use practices coupled with abiotic stresses such as drought, high and low temperature stress and salinity stress (Wang and Gao, 2003; Niu et al., 2016). Leymus chinensis is known to be tolerant to a range of abiotic stresses most importantly salinity stress (Chen et al., 2013). Although L. chinensis has great potential rehabilitation and restoration of grasslands, nonetheless, salt stress is imposing numerous detrimental effects on yield and quality of L. chinensis (Liu and Qi, 2004; Li et al., 2015).

Salt stress impose detrimental impacts on plant growth and development through osmotic and ionic stress which obstructs the physiological and biochemical events going on in plants (Misra et al., 2002; Munns, 2005). It usually causes an over accumulation of $\mathrm{Na}^{+}$and $\mathrm{Cl}^{-}$in plant cells, which results in aggravated generation of reactive oxygen species (ROS) such as singlet oxygen $\left(\mathrm{O}^{*}\right)$, super oxide radical $\left(\mathrm{O}^{-1}\right)$, hydrogen peroxide $\left(\mathrm{H}_{2} \mathrm{O}_{2}\right)$ and hydroxyl radical $\left(\mathrm{OH}^{-}\right)$due to impaired metabolic activities. Over production of ROS causes cellular injury through oxidative damage to the membranes and organic molecules (Ashraf, 2009). Salinity stress adversely hinders the ion uptake and perturbs the photosynthetic efficiency due to decreased biosynthesis of photosynthetic pigments and stomatal oscillations, which ultimately consequences in impaired plant growth and development (Iqbal and Ashraf, 2010). Plants maintain osmotic and ion balance by regulating the absorption, translocation and sequestration of the salt ions and accumulation of certain organic solutes (Flowers and Colmer, 2008). In response to salinity stress plants produce and accumulate osmoprotectants such as proline and glycine betaine to combat with osmotic stress by allowing improved water uptake, scavenging free radicals (Ashraf and Foolad, 2007) and protect the biological membranes and organic macromolecules from oxidative damage through ROS (Hoekstra et al., 2001). Antioxidants are biosynthesized and act as a first line of defense against the ROS, which are located in almost all cell organelles where ROS is produced (Liau et al., 2007).

5-Aminolevulinic acid (ALA) is a key precursor in the synthesis of porphyrin compounds viz. chlorophyll and heme (Wang et al., 2005; Awad, 2008). Plants exposed to stressed conditions such as salinity perform better pertaining to growth and development 
when treated with ALA (Watanabe et al., 2000; Zhang et al., 2006). Exogenous application of ALA improves the tissue water status, stimulates the biosynthesis of photosynthetic pigments and exacerbates the antioxidants activity, which lowers the production of ROS (Memon et al., 2009; Naeem et al., 2010; Zhang et al., 2012). These events are controlled by gene expression and production of mRNA for antioxidant enzyme synthesis, which is mediated by ALA (Balestrasse et al., 2010). Based upon above discussed considerations, a study was carried to assess the role of ALA in the modulation of morphological, physiological and metabolic attributes of L. chinensis plants exposed to salinity stress and to determine the degree of stress tolerance accomplished.

\section{MATERIALS AND METHODS}

A pot experiment was conducted in greenhouse incubator, College of Agronomy and Biotechnology, Southwest University, Chongqing, China, during 2014. Seeds of Leymus chinensis were collected from Ecological Experimental Station of L. chinensis natural distribution community, Inner Mongolia, China. The seeds were dried at room temperature, put in bags, and stored at $4{ }^{\circ} \mathrm{C}$. Seeds were sown in pots in incubator. Seedlings were transplanted to sand culture and 35 seedlings were transplanted for each pot. Seedlings were supplied with Hoagland nutrient solution every $5 \mathrm{~d}$ to ensure suitable nutrient supply. After the seedlings attained 15-18 $\mathrm{cm}$ height, thinning was done to keep 25 seedlings per pot. Three concentrations of ALA viz. 10, 50, and $100 \mathrm{mg} \mathrm{L}^{-1}$ were sprayed to the L. chinensis plants and distilled water was used as control for comparison. Salt stress treatment was imposed at the concentrations of $150 \mathrm{mmol} \mathrm{L}^{-1} \mathrm{NaCl}$. Second spray of ALA was carried out $4 \mathrm{~d}$ after first treatment. The treatment details are given in Table 1. The experiment consisted of eight treatments of ALA under normal and saline conditions and each was replicated thrice. Morphological, physiological and biochemical traits were recorded $7 \mathrm{~d}$ after treatment.

Data pertaining to morphological traits were measured by uprooting L. chinensis plants from each pot. Following uprooting plants were rinsed thoroughly with tap water and then 2-3 times with distilled water. Filter paper was used to absorb the adhered water to the plants. Plant height was measured from tip of the stem to the parietal lobe at base

Table 1. Experimental treatments of 5-aminolevulinic acid (ALA) application under non-saline and saline conditions.

\begin{tabular}{cccc}
\hline & Treatment & $\mathrm{NaCl}$ concentration & ALA concentration \\
\hline \multirow{5}{*}{ W group } & $\mathrm{mmol} \mathrm{\textrm {L } ^ { - 1 }}$ & $\mathrm{mg} \mathrm{L}^{-1}$ \\
& $\mathrm{~W}+\mathrm{A}_{0}$ & 0 & 0 \\
& $\mathrm{~W}+\mathrm{A}_{1}$ & 0 & 10 \\
& $\mathrm{~W}+\mathrm{A}_{2}$ & 0 & 50 \\
& $\mathrm{~W}+\mathrm{A}_{3}$ & 0 & 100 \\
S group & $\mathrm{S}+\mathrm{A}_{0}$ & 150 & 0 \\
& $\mathrm{~S}+\mathrm{A}_{1}$ & 150 & 10 \\
& $\mathrm{~S}+\mathrm{A}_{2}$ & 150 & 50 \\
& $\mathrm{~S}+\mathrm{A}_{3}$ & 150 & 100 \\
\hline
\end{tabular}

ALA: 5-Aminolevulinic acid, W: water, A: ALA treatment, S: salt stress plants. Leaf length, width, and area were determined by using leaf area analysis/scanner (MSD-971, Beijing Steve Macbeth Instrument Co. Ltd., China). Plants were weighed to determine fresh weight followed by drying in oven at $105{ }^{\circ} \mathrm{C}$ for $30 \mathrm{~min}$ and then at $65^{\circ} \mathrm{C}$ till constant weight to determine the seedling dry weight. Root/shoot ratio was determined by using the shoot and root dry weights. Plant water content was assessed by using the formula:

Water content $(\%)=($ Fresh weight - Dry weight $) /($ Fresh weight $) \times 100$

Relative electrical conductivity was measured by the method of Nayyar et al. (2005), root activity by 2,3,5-triphenyltetrazolium chloride (TTC) method (Higa et al., 2010), and photosynthetic pigments viz. chlorophyll $\mathrm{a}$ and $\mathrm{b}$, total chlorophyll, and carotenoid content were determined by using the method of Wellburn (1994). Soluble protein content was assayed by using Coomassie brilliant blue method (Bradford, 1976) and soluble sugars were quantified by anthrone color method (Li et al., 2008). The malondialdehyde (MDA) content was assessed by thiobarbituric acid (TBA) assay (De Vos et al., 1991). Proline content was determined by ninhydrin method (Bates et al., 1973). Enzymatic antioxidants viz. superoxide dismutase (SOD), catalase (CAT), peroxidase (POD), ascorbate peroxidase (APX) and glutathione reductase (GR) were determined by using the method of Parida et al. (2004).

Microsoft Excel and statistical software program SPSS 19.0 (IBM, Armonk, New York, USA) was used for analysis of data collected and treatments' means were compared by Duncan's multiple range test. Two-way ANOVA was used to analyze interactions between salt stress and ALA treatment.

\section{RESULTS}

The results revealed that plant growth was affected significantly by salinity stress and ALA application. It was noticed that leaf length, leaf electrical conductivity and root activity of L. chinensis plants were increased when exposed to salinity stress; however, leaf area, plant dry weight and water contents were reduced by salinity stress as compared to control. Plant fresh weight was did not affect by salinity stress, while ALA application imposed significant effect. Surprisingly, plant height and root/shoot ratio were not significantly affected by salinity stress as well as by ALA treatment. Application of ALA exerted growth promoting effect on L. chinensis plants. An increase in leaf length, leaf area, plant fresh and dry weight, water contents and root activity and a decrease in leaf electrical conductivity occurred when L. chinensis plants were treated with ALA under both normal and saline conditions and application of $100 \mathrm{mg} \mathrm{L}^{-1}$ ALA was most beneficial (Tables 2 and 3).

Salinity stress significantly disrupted the biosynthesis of photosynthetic pigments while ALA application showed an ameliorative effect on L. chinensis plants. Total chlorophyll, chlorophyll $a$ and $b$, and carotenoids were decreased under salt stress as compared to control. Treatments of L. chinensis plants with ALA improved biosynthesis of photosynthetic 
pigments under both normal and saline conditions. Application of 10 and $100 \mathrm{mg} \mathrm{L}^{-1}$ ALA performed better under normal and saline conditions, respectively (Figure 1).

Leymus chinensis plants exposed to salt stress resulted in significantly higher MDA and proline accumulation and lower soluble protein and sugar content. Conversely, ALA application reduced the MDA content, while improving the free proline, soluble protein and sugar content under both nonsaline and saline conditions. The MDA content was lowest by $50 \mathrm{mg} \mathrm{L}^{-1}$ ALA application under both non-saline and saline conditions. The proline content was highest by $50 \mathrm{mg} \mathrm{L}^{-1}$ ALA application under saline conditions. Soluble protein was improved by 10 and $100 \mathrm{mg} \mathrm{L}^{-1}$ ALA; while 50 and $10 \mathrm{mg} \mathrm{L}^{-1}$ ALA treatments were most beneficial in improving soluble sugar content as compared to control under both non-saline and saline conditions, respectively (Table 4).

Salt stress and ALA application significantly affected activity of antioxidants viz. APX, GR, POD and SOD.

Table 2. Effect of exogenous 5-aminolevulinic acid (ALA) on morphological traits and leaf electrical conductivity of Leymus chinensis plants under salinity stress.

\begin{tabular}{llccc}
\hline Treatment & $\begin{array}{c}\text { Plant } \\
\text { height }\end{array}$ & $\begin{array}{c}\text { Leaf } \\
\text { length }\end{array}$ & $\begin{array}{c}\text { Leaf } \\
\text { area }\end{array}$ & $\begin{array}{c}\text { Leaf electrical } \\
\text { conductivity }\end{array}$ \\
\cline { 2 - 5 } $\mathrm{W}+\mathrm{A}_{0}$ & $34.50 \pm 1.00 \mathrm{bc}$ & $19.69 \pm 0.44 \mathrm{~b}$ & $7.96 \pm 1.18 \mathrm{c}$ & $0.066 \pm 0.005 \mathrm{c}$ \\
$\mathrm{W}+\mathrm{A}_{1}$ & $34.33 \pm 1.80 \mathrm{bc}$ & $20.80 \pm 0.13 \mathrm{~b}$ & $9.81 \pm 0.79 \mathrm{bc}$ & $0.062 \pm 0.009 \mathrm{c}$ \\
$\mathrm{W}+\mathrm{A}_{2}$ & $35.75 \pm 1.06 \mathrm{abc}$ & $20.49 \pm 0.30 \mathrm{~b}$ & $11.11 \pm 0.79 \mathrm{~b}$ & $0.062 \pm 0.003 \mathrm{c}$ \\
$\mathrm{W}+\mathrm{A}_{3}$ & $37.17 \pm 1.84 \mathrm{ab}$ & $16.21 \pm 0.69 \mathrm{c}$ & $17.01 \pm 1.02 \mathrm{a}$ & $0.062 \pm 0.008 \mathrm{c}$ \\
$\mathrm{S}+\mathrm{A}_{0}$ & $31.17 \pm 2.24 \mathrm{c}$ & $20.49 \pm 0.69 \mathrm{~b}$ & $7.61 \pm 1.61 \mathrm{c}$ & $0.159 \pm 0.006 \mathrm{a}$ \\
$\mathrm{S}+\mathrm{A}_{1}$ & $35.43 \pm 1.78 \mathrm{abc}$ & $25.05 \pm 0.06 \mathrm{a}$ & $8.04 \pm 1.61 \mathrm{c}$ & $0.124 \pm 0.009 \mathrm{~b}$ \\
$\mathrm{~S}+\mathrm{A}_{2}$ & $38.01 \pm 0.96 \mathrm{ab}$ & $25.83 \pm 0.24 \mathrm{a}$ & $9.00 \pm 0.84 \mathrm{bc}$ & $0.071 \pm 0.006 \mathrm{c}$ \\
$\mathrm{S}+\mathrm{A}_{3}$ & $40.00 \pm 1.60 \mathrm{a}$ & $19.73 \pm 0.38 \mathrm{~b}$ & $10.84 \pm 1.02 \mathrm{~b}$ & $0.059 \pm 0.005 \mathrm{c}$ \\
$\mathrm{NaCl}$ conc. & $0.06^{\mathrm{NS}}$ & $146.95^{* *}$ & $70.75^{* *}$ & $9.64^{*}$ \\
$\mathrm{ALA} \mathrm{conc}$. & $0.16^{\mathrm{NS}}$ & $59.27^{* *}$ & $70.84^{* *}$ & $4.27^{\mathrm{NS}}$ \\
$\mathrm{NaCl} \times \mathrm{ALA}$ & $2.96^{\mathrm{NS}}$ & $26.58^{* *}$ & $18.68^{* *}$ & $4.75^{*}$ \\
\hline
\end{tabular}

Values in the table are mean $\pm \operatorname{SE}(n=3)$. Values followed by different letters within each column are significantly different according to Duncan's multiple range test $(\mathrm{P}<0.05)$.

${ }^{*}$, ${ }^{* *}$ Significant at the 0.05 and 0.01 probability levels, respectively, NS: nonsignificant difference.

ALA conc: ALA concentration.
Activity of CAT was not significantly affected by $\mathrm{NaCl}$ salinity as well by interaction of salinity and ALA application; however, ALA application enhanced significant effect on its activity (Table 5). It was noticed that activity of antioxidants was reduced by salinity stress as compared to control. Conversely, application of ALA ameliorated the effects of salinity stress on enzymatic antioxidants activity; furthermore, it also boosted the activity of antioxidants in $L$. chinensis plants under no salt stress. Under normal conditions, activity of APX and CAT was improved most by $10 \mathrm{mg} \mathrm{L}^{-1}$ ALA application; however, $50 \mathrm{mg} \mathrm{L}^{-1}$ ALA treatment also imparted similar effect on CAT activity. Application of 100 $\mathrm{mg} \mathrm{L}^{-1}$ ALA exacerbated the activity of GR, SOD, and POD. Under saline conditions, activity of APX was enhanced most by $100 \mathrm{mg} \mathrm{L}^{-1}$ ALA, activity of GR was improved most by $10 \mathrm{mg} \mathrm{L}^{-1}$ ALA and activity of SOD, CAT and POD was exaggerated most by $50 \mathrm{mg} \mathrm{L}^{-1}$ ALA application (Figure 2).

\section{DISCUSSION}

A reduction in plant growth and development is perceived when plants are exposed to salinity stress, as a result of decreased photosynthetic efficiency of plants, which may occur due to decrease in stomatal conductance and/or disruption of photosynthetic machinery by ROS. Under stressed conditions, ROS are aggressively produced while antioxidants activity is slowed down leading to destructive damage to membranes through lipid peroxidation (Mittler, 2002). It has been established that all the physiological and metabolic changes within the plants are dependent on gene expression, which is further controlled by plant growth regulators thus emphasizing their importance as a plant growth controlling factor under stressed conditions (Zhen et al., 2012). Results of our experiment indicated that growth and development of L. chinensis plants was impaired by salt stress, which was improved by the foliar application of ALA (Tables 2 and 3). Similar results were reported by Naeem et al. (2010), who noticed an improvement in biomass production by ALA treatment of Brassica napus plants

Table 3. Effect of exogenous 5-aminolevulinic acid (ALA) on fresh weight, dry weight, water contents, root shoot ratio, and root activity of Leymus chinensis plants under salinity stress.

\begin{tabular}{|c|c|c|c|c|c|}
\hline Treatment & Fresh weight & Dry weight & Water contents & Root shoot ratio & Root activity \\
\hline & & & $\%$ & & $\mu \mathrm{g} \mathrm{g}^{-1} \mathrm{~h}^{-1}$ \\
\hline $\mathrm{W}+\mathrm{A}_{0}$ & $0.389 \pm 0.003 b$ & $0.138 \pm 0.006 \mathrm{e}$ & $65.83 \pm 0.38 b$ & $0.33 \pm 0.05 \mathrm{a}$ & $41.69 \pm 0.18 \mathrm{e}$ \\
\hline $\mathrm{W}+\mathrm{A}_{1}$ & $0.416 \pm 0.019 \mathrm{ab}$ & $0.161 \pm 0.009 d$ & $64.10 \pm 1.12 b$ & $0.41 \pm 0.08 \mathrm{a}$ & $73.09 \pm 0.70 b c$ \\
\hline $\mathrm{W}+\mathrm{A}_{2}$ & $0.491 \pm 0.011 \mathrm{ab}$ & $0.175 \pm 0.006 \mathrm{~d}$ & $89.38 \pm 2.96 a$ & $0.43 \pm 0.01 \mathrm{a}$ & $76.98 \pm 0.15 b c$ \\
\hline $\mathrm{W}+\mathrm{A}_{3}$ & $0.621 \pm 0.061 \mathrm{a}$ & $0.289 \pm 0.003 \mathrm{a}$ & $61.97 \pm 2.72 b$ & $0.51 \pm 0.06 \mathrm{a}$ & $98.67 \pm 0.87 \mathrm{a}$ \\
\hline $\mathrm{S}+\mathrm{A}_{0}$ & $0.399 \pm 0.011 b$ & $0.135 \pm 0.004 \mathrm{e}$ & $33.19 \pm 7.60 \mathrm{c}$ & $0.33 \pm 0.03 a$ & $56.99 \pm 0.64 d$ \\
\hline $\mathrm{S}+\mathrm{A}_{1}$ & $0.424 \pm 0.082 \mathrm{ab}$ & $0.157 \pm 0.008 d$ & $60.36 \pm 5.70 \mathrm{~b}$ & $0.37 \pm 0.06 \mathrm{a}$ & $70.36 \pm 0.69 \mathrm{~cd}$ \\
\hline $\mathrm{S}+\mathrm{A}_{2}$ & $0.426 \pm 0.0491 \mathrm{ab}$ & $0.213 \pm 0.005 c$ & $67.01 \pm 1.14 \mathrm{~b}$ & $0.42 \pm 0.05 \mathrm{a}$ & $68.77 \pm 0.61 \mathrm{~cd}$ \\
\hline $\mathrm{S}+\mathrm{A}_{3}$ & $0.476 \pm 0.092 \mathrm{ab}$ & $0.258 \pm 0.012 b$ & $60.32 \pm 2.50 b$ & $0.46 \pm 0.13 a$ & $85.49 \pm 0.57 \mathrm{ab}$ \\
\hline $\mathrm{NaCl}$ conc. & $5.67^{\mathrm{NS}}$ & $0.08^{\mathrm{NS}}$ & $23.19^{* *}$ & $0.18^{\mathrm{NS}}$ & $8.85^{*}$ \\
\hline ALA conc. & $9.99^{*}$ & $148.19^{* *}$ & $13.09^{* *}$ & $0.41^{\mathrm{NS}}$ & $36.44^{* *}$ \\
\hline $\mathrm{NaCl} \times \mathrm{ALA}$ & $0.23^{\mathrm{NS}}$ & $7.23^{*}$ & $8.65^{* *}$ & $0.54^{\mathrm{NS}}$ & $11.01^{* *}$ \\
\hline
\end{tabular}

Values in the table are mean \pm SE $(n=3)$. Values followed by different letters within each column are significantly different according to Duncan's multiple range test $(\mathrm{P}<0.05)$.

${ }^{*},{ }^{*}$ Significant at the 0.05 and 0.01 probability levels, respectively, NS: nonsignificant difference.

ALA conc: ALA concentration. 
Figure 1. Effect of exogenous 5-aminolevulinic acid (ALA) on photosynthetic pigments of Leymus chinensis plants under salinity stress.

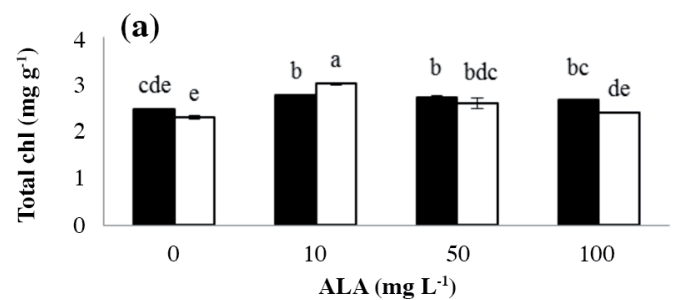

(c)

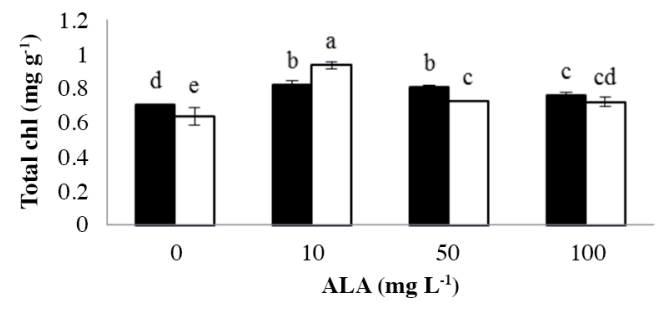

(b)

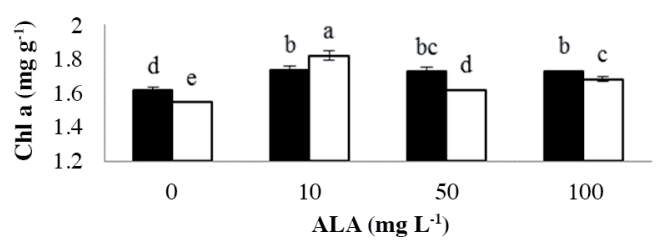

(d)

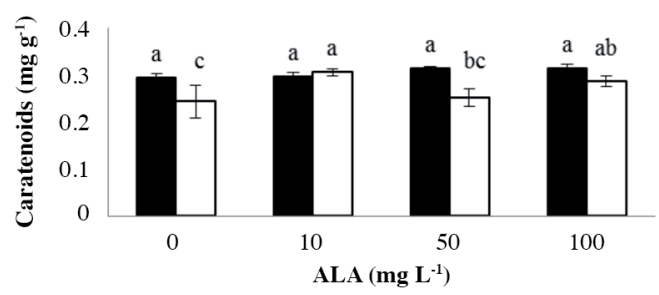

口: W+A; $\square:$ S+A. Bars followed by different letters within each trait are significantly different according to Duncan's multiple range test $(\mathrm{P}<0.05)$.

Chl: Chlorophyll, W: water, A: ALA treatment, S: salt stress.

Table 4. Effect of exogenous 5-aminolevulinic acid (ALA) on accumulation of malondialdehyde (MDA) and osmolytes of Leymus chinensis plants under salinity stress.

\begin{tabular}{|c|c|c|c|c|}
\hline Treatment & MDA & $\begin{array}{c}\text { Free } \\
\text { proline }\end{array}$ & $\begin{array}{l}\text { Soluble } \\
\text { protein }\end{array}$ & $\begin{array}{c}\text { Soluble } \\
\text { sugars }\end{array}$ \\
\hline & $\mathrm{nmol} \mathrm{g}^{-1}$ & $\mu \mathrm{g} \mathrm{g}^{-1}$ & \multicolumn{2}{|c|}{$\longrightarrow \mathrm{mg} \mathrm{g}^{-1}$} \\
\hline $\mathrm{W}+\mathrm{A}_{0}$ & $16.56 \pm 0.53 \mathrm{~cd}$ & $94.51 \pm 4.24 \mathrm{~d}$ & $27.17 \pm 0.90 \mathrm{a}$ & $11.58 \pm 0.32 b c$ \\
\hline $\mathrm{W}+\mathrm{A}_{1}$ & $15.98 \pm 0.39 \mathrm{~cd}$ & $102.07 \pm 2.02 \mathrm{~d}$ & $28.00 \pm 0.11 \mathrm{a}$ & $11.62 \pm 0.81 b c$ \\
\hline $\mathrm{W}+\mathrm{A}_{2}$ & $15.17 \pm 0.95 \mathrm{~d}$ & $291.38 \pm 1.84 b$ & $19.42 \pm 0.77 b$ & $17.14 \pm 0.17 \mathrm{a}$ \\
\hline $\mathrm{W}+\mathrm{A}_{3}$ & $15.46 \pm 0.94 \mathrm{~cd}$ & $399.64 \pm 3.37 \mathrm{a}$ & $16.88 \pm 0.64 c$ & $12.13 \pm 0.09 b$ \\
\hline $\mathrm{S}+\mathrm{A}_{0}$ & $20.10 \pm 1.03 \mathrm{a}$ & $256.95 \pm 3.87 b c$ & $14.52 \pm 0.04 d$ & $11.51 \pm 0.95 b c$ \\
\hline $\mathrm{S}+\mathrm{A}_{1}$ & $19.29 \pm 0.13 \mathrm{ab}$ & $282.75 \pm 3.59 b c$ & $15.35 \pm 0.75 \mathrm{~cd}$ & $15.88 \pm 0.22 \mathrm{a}$ \\
\hline $\mathrm{S}+\mathrm{A}_{2}$ & $17.50 \pm 1.12 b c$ & $293.27 \pm 2.13 b$ & $15.66 \pm 0.28 \mathrm{~cd}$ & $10.20 \pm 0.21 \mathrm{c}$ \\
\hline $\mathrm{S}+\mathrm{A}_{3}$ & $19.56 \pm 1.23 \mathrm{ab}$ & $249.62 \pm 4.75 c$ & $20.76 \pm 0.84 b$ & $10.17 \pm 0.43 \mathrm{c}$ \\
\hline \multicolumn{2}{|c|}{$\mathrm{NaCl}$ conc. $\quad 5.14^{*}$} & $41.68^{* *}$ & $260.17^{* *}$ & $11.21^{*}$ \\
\hline ALA conc. & $0.49^{\mathrm{NS}}$ & $21.90^{* *}$ & $32.94^{* *}$ & $24.82^{* *}$ \\
\hline $\mathrm{NaCl} \times \mathrm{ALA}$ & $18.46^{* *}$ & $142.86^{* *}$ & $96.64^{* *}$ & $68.83^{* *}$ \\
\hline
\end{tabular}

Values in the table are mean $\pm \mathrm{SE}(n=3)$. Values followed by different letters within each column are significantly different according to Duncan's multiple range test $(\mathrm{P}<0.05)$.

* ${ }^{* *}$ Significant at the 0.05 and 0.01 probability levels, respectively, NS: nonsignificant difference.

ALA conc: ALA concentration.

Table 5. Summary of the ANOVA of the effect of exogenous 5-aminolevulinic acid (ALA), salt stress on antioxidant enzymes activity of Leymus chinensis plants under salinity stress.

\begin{tabular}{lccc}
\hline $\begin{array}{l}\text { Antioxidant } \\
\text { enzymes }\end{array}$ & $\mathrm{NaCl}$ & $\mathrm{ALA}$ & $\mathrm{NaCl} \times \mathrm{ALA}$ \\
\hline $\mathrm{APX}$ & $12.30^{* *}$ & $6.56^{*}$ & $16.76^{* *}$ \\
GR & $13.69^{* *}$ & $8.66^{* *}$ & $12.80^{* *}$ \\
POD & $7.31^{*}$ & $10.14^{* *}$ & $23.90^{* *}$ \\
SOD & $596.88^{* *}$ & $25.81^{* *}$ & $99.66^{* *}$ \\
CAT & $0.15^{\mathrm{NS}}$ & $5.28^{*}$ & $3.17^{\mathrm{NS}}$ \\
\hline
\end{tabular}

* ${ }^{* *}$ Significant at the 0.05 and 0.01 probability levels, respectively, NS: nonsignificant difference.

APX: Ascorbate peroxidase, GR: glutathione reductase, POD: peroxidase, SOD: superoxide dismutase, CAT: catalase, ALA: 5-aminolevulinic acid. exposed to salinity stress. Zhang et al. (2008) also reported an increase in shoot length and biomass production of $B$. napus plant on ALA treatment under herbicide stress.

Abiotic stresses considerably affectupon the photosynthetic efficiency either by disrupting the photosynthetic pigments such as chlorophyll and carotenoids or by affecting the stomatal conductance. Decline in activities of chlorophyll, carotenoids, chlorophyll fluorescence and photosystem II occurs due to salinity stress (Santos et al., 2001). In our study, biosynthesis of photosynthetic pigments was lowered in L. chinensis plants by salinity stress, which was improved by application of ALA (Figure 1). The ALA is precursor of heme containing photosynthetic pigments, which may be the reason of improvement in chlorophyll and carotenoids content by ALA treatment (Wang et al., 2005; Pavlovic et al., 2009). Results similar to ours were reported by Youssef and Awad (2008), who perceived an enhanced synthesis of photosynthetic pigments by the application of ALA to Phoenix dactylifera plants exposed to salinity stress. Naeem et al. (2012) also reported that treatment of B. napus with ALA under salinity stress improved the chlorophyll content.

Membrane lipid peroxidation due to the action of ROS results in enhanced level of MDA. Under stressed conditions there is over production of ROS, more membrane lipid peroxidation and thus more accumulation of MDA (Zhang et al., 2011). In present study, exaggerated levels of MDA were perceived in L. chinensis plants due to salinity stress, however, it was undermined by the application of ALA (Table 4). Zhang et al. (2008) reported similar results that MDA content was lowered in $B$. napus plants by treatment with ALA at low concentration. The treatment of ALA to plants also was associated with reduction in the synthesis of ROS (Akram et al., 2012), and results in the decreased oxidative stress due to more stable biological membranes 
Figure 2. Effect of exogenous 5-aminolevulinic acid (ALA) on antioxidant enzymes activity of Leymus chinensis plants under salinity stress.
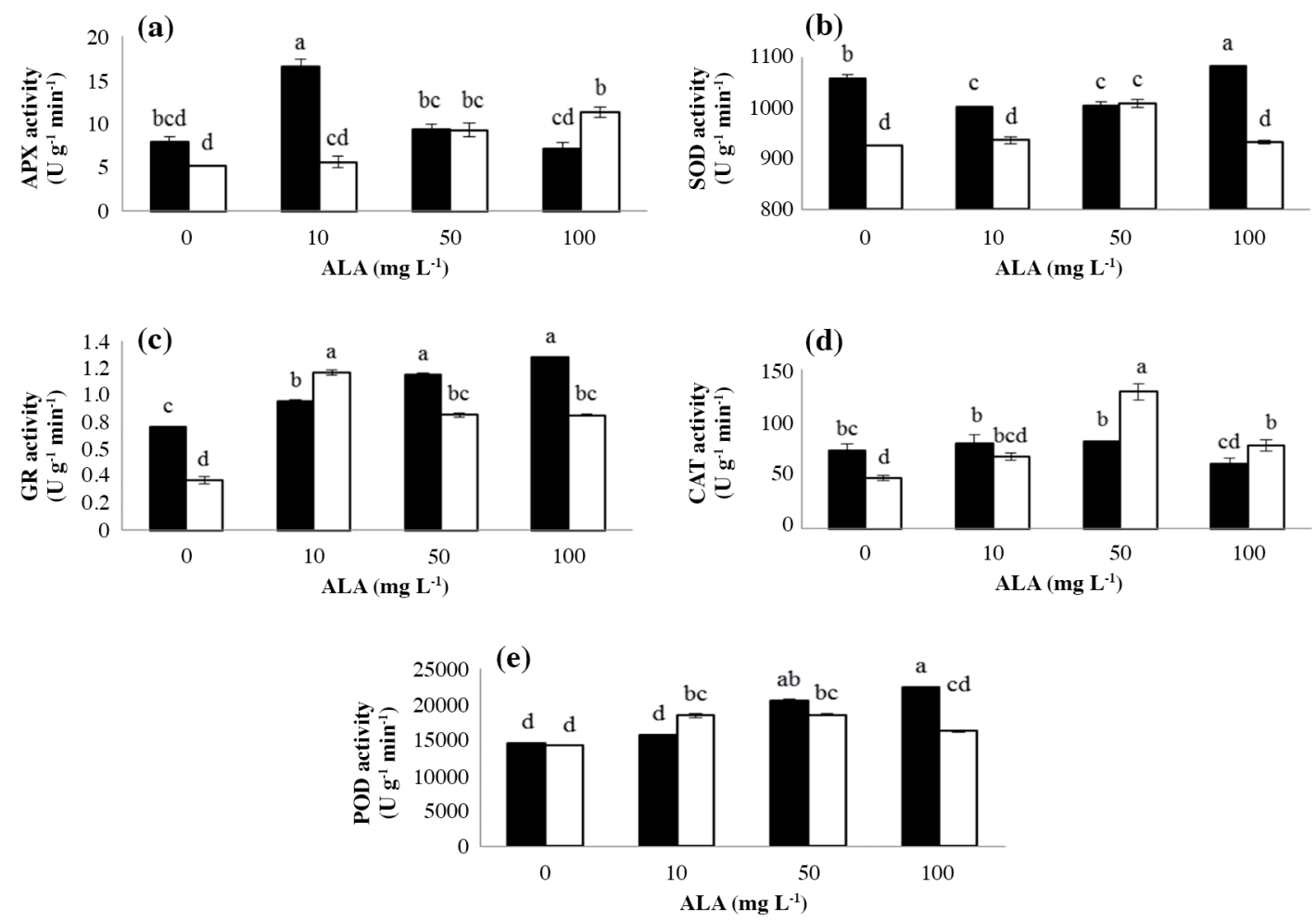

口: W+A; $\square$ : S+A. Bars followed by different letters within each trait are significantly different according to Duncan's multiple range test $(\mathrm{P}<0.05)$. APX: Ascorbate peroxidase, GR: glutathione reductase, POD: peroxidase, SOD: superoxide dismutase, CAT: catalase, W: water, A: ALA treatment, S: salt stress.

(Balestrasse et al., 2010). Plants maintain tissue water status and protect biological membranes and organic molecules from the hazardous effects of ROS under stressed conditions by the production and accumulation of osmolytes such as proline, soluble sugars, and proteins (Anuradha and Rao, 2007). Our results revealed an increase in the accumulation of osmolytes in L. chinensis plants in response to salinity stress, which were further improved by ALA application (Table 4). Korkmaz et al. (2010) reported similar results that ALA treatment of pepper seedlings exposed to chilling stress improved the synthesis and accumulation of osmolytes.

The protection against oxidative stress induced by generation of toxic ROS is achieved by the plants through the coordinated action of enzymatic and non-enzymatic antioxidants (Jaleel et al., 2009), which have been found to play an important role in the development of tolerance under salt stress conditions. Our study results showed that salinity stress lowered the activity of enzymatic antioxidants such as APX, GR, SOD, CAT, and POD. Nonetheless, exogenous application of ALA improved the activity of antioxidants (Figure 2). It is known that antioxidants activity is regulated by gene expression mediated by plant growth regulators (Zhen et al., 2012). Nishihara et al. (2003) reported that antioxidants activity in spinach plants was stimulated by ALA treatment under salinity stress. Li et al. (2011) also reported an exaggerated activity of antioxidant enzymes in cucumber leaves by application of ALA.

\section{CONCLUSION}

The results revealed that salinity stress negatively affected growth, physiology and biochemistry of Leymus chinensis plants. However, exogenous application of 5-aminolevulinic acid (ALA) ameliorated the perturbing effects of salt stress on growth, biosynthesis of photosynthetic pigments, osmolytes and antioxidants, and reduced the lipid peroxidation and malondialdehyde (MDA) level; and it was concentration dependent. The results of present study conclude that exogenous application of ALA helps the plants in attaining tolerance against salt stress. It was suggested that L. chinensis plants were treated with ALA application of $50-100 \mathrm{mg} \mathrm{L}^{-1}$ was more beneficial under both normal and saline conditions.

\section{ACKNOWLEDGEMENTS}

The authors are grateful to National Key Basic Research Program of China (2014CB138806) along with Crop Germplasm Resources Utilization and Innovation Base Program of the 111 Project of China (104510-205001).

\section{REFERENCES}

Akram, N.A., M. Ashraf, and F. Al-Qurainy. 2012. Aminolevulinic acid-induced changes in some key physiological attributes and activities of antioxidant enzymes in sunflower (Helianthus annuus L.) plants under saline regimes. Scientia Horticulturae 142:143-148. 
Anuradha, S., and S.S.R. Rao. 2007. The effect of brassinosteroids on radish (Raphanus sativus L.) seedlings growing under cadmium stress. Plant Soil and Environment 53:465-472.

Ashraf, M. 2009. Biotechnological approach of improving plant salt tolerance using antioxidants as markers. Biotechnology Advances 27:84-93.

Ashraf, M., and M.R. Foolad. 2007. Roles of glycinebetaine and proline in improving plant abiotic stress resistance. Environmental and Experimental Botany 59:206-216.

Awad, M.A. 2008. Promotive effects of a 5-aminolevulinic acidbased fertilizer on growth of tissue culture-derived date palm plants (Phoenix dactylifera $\mathrm{L}$.) during acclimatization. Scientia Horticulturae 118:48-52.

Balestrasse, K.B., M.L. Tomaro,A. Batlle, and G.O. Noriega. 2010. The role of 5-aminolevulinic acid in the response to cold stress in soybean plants. Phytochemistry 71:2038-2045.

Bates, L.S., R.P. Waldren, and I.D. Teare. 1973. Rapid determination of free proline for water-stress studies. Plant and Soil 39:205-207.

Bradford, M.M. 1976. A rapid and sensitive method for the quantitation of microgram quantities of protein utilizing the principle of protein-dye binding. Analytical Biochemistry 72:248-254.

Chen, S., X. Huang, X. Yan, Y. Liang, Y. Wang, X. Li, et al. 2013. Transcriptome analysis in sheepgrass (Leymus chinensis): A dominant perennial grass of the Eurasian Steppe. PloS One 8:1-15.

De Vos, C., H.M. Schat, M.A.D. Waal, R. Vooijs, and W. Ernst. 1991. Increased resistance to copper-induced damage of the root plasma membrane in copper tolerant Silene cucubalus. Plant Physiology 82:523-528.

Flowers, T.J., and T.D. Colmer. 2008. Salinity tolerance in halophytes. New Phytologist 179:945-963.

Higa, A., Y. Mori, and Y. Kitamura. 2010. Iron deficiency induces changes in riboflavin secretion and the mitochondrial electron transport chain in hairy roots of Hyoscyamus albus. Journal of Plant Physiology 167:870-878.

Hoekstra, F.A., E.A. Golovina, and J. Butinik. 2001. Mechanism plant desiccation tolerance. Trends in Plant Science 6:431-438.

Iqbal, M., and M. Ashraf. 2010. Changes in hormonal balance: a possible mechanism of pre-sowing chilling-induced salt tolerance in spring wheat. Journal of Agronomy and Crop Science 196:440-454.

Jaleel, C.A., R. Ksouri, G. Raghupathi, M. Paramasivam, I. Jallali, H.J. Al-Juburi, et al. 2009. Antioxidant defense responses: physiological plasticity in higher plants under abiotic constraints. Acta Physiologia Plantarum 31:427-436.

Korkmaz, A., Y. Korkmaz, and A.R. Demirkiran. 2010. Enhancing chilling stress tolerance of pepper seedlings by exogenous application of 5-aminolevulinic acid. Environmental and Experimental Botany 67:495-501.

Li, J.H., A.A. Shakeel, M.R. Liu, J.H. Niu, R. Wang, J.X. Song, et al. 2015. Modulation of morpho-physiological traits of Leymus chinensis (trin.) through exogenous application of brassinolide under salt stress. The Journal of Animal and Plant Sciences 25:1055-1062.

Li, M.H., W.F. Xiao, P.L. Shi, S.G. Wang, Y.D. Zhong, X.L. Liu, et al. 2008. Nitrogen and carbon source-sink relationships in trees at the Himalayan treelines compared to lower elevations. Plant, Cell \& Environment 31(10):1377-1387.

Li, D.M., J. Zhang, W.J Sun, Q. Li, A.H. Dai, and J.G. Bai. 2011. 5-Aminolevulinic acid pretreatment mitigates drought stress of cucumber leaves through altering antioxidant enzyme activity. Scientia Horticulturae 130:820-828.
Liau, Y.J., L. Wen, J.F. Shaw, and C.T. Lin. 2007. A highly stable cambialistic-superoxide dismutase from Antrodia camphorata: Expression in yeast and enzyme properties. Journal of Biotechnology 131:84-91.

Liu, G.S., and D.M. Qi. 2004. Research progress on the biology of Leymus chinensis. Acta Prataculturae Sinica 13:6-11.

Memon, S.A., X.L. Hou, L.G. Wang, and Y. Li. 2009. Promotive effect of 5-aminolevulinic acid on chlorophyll, antioxidative enzymes and photosynthesis of Pakchoi (Brassica campestris ssp. chinensis var. communis Tsen et Lee). Acta Physiologiae Plantarum 31:51-57.

Misra, A.N., A.K. Biswal, and M. Misra. 2002. Physiological, biochemical and molecular aspects of water stress responses in plants, and the bio-technological applications. ProceedingsNational Academy of Sciences India Section B 72(2):115-134.

Mittler, R. 2002. Oxidative stress, antioxidants and stress tolerance. Trends in Plant Science 7:405-410.

Munns, R. 2005. Genes and salt tolerance: bringing them together. New Phytologist 167:645-663.

Naeem, M.S., Z.L. Jin, G.L. Wan, D. Liu, H.B. Liu, K. Yoneyama, et al. 2010. 5-Aminolevulinic acid improves photosynthetic gas exchange capacity and ion uptake under salinity stress in oilseed rape (Brassica napus L.) Plant and Soil 332:405-415.

Naeem, M.S., H. Warusawitharana, H.B. Liu, D. Liu, R. Ahmad, E.A. Waraich, et al. 2012. 5-Aminolevulinic acid alleviates the salinity-induced changes in Brassica napus as revealed by the ultrastructural study of chloroplast. Plant Physiology and Biochemistry 57:84-92.

Nayyar, H., T.S. Bains, and S. Kumar. 2005. Chilling stressed chickpea seedlings: effect of cold acclimation, calcium and abscisic acid on cryoprotective solutes and oxidative damage. Environmental and Experimental Botany 54:275-285.

Nishihara, E., K. Kondo, M.M. Parvez, K. Takahashi, K. Watanabe, and K. Tanaka. 2003. Role of 5-aminolevulinic acid (ALA) on active oxygen-scavenging system in $\mathrm{NaCl}$-treated spinach (Spinacia oleracea). Journal of Plant Physiology 160:1085-1091.

Niu, J.H., A.A. Shakeel, R. Wang, J.H. Li, M.R. Liu, J.X. Song, et al. 2016. Exogenous application of brassinolide can alter morphological and physiological traits of Leymus chinensis (Trin.) Tzvel. under room and high temperatures. Chilean Journal of Agricultural Research 76:27-33.

Parida, A.K., A.B. Das, and P. Mohanty. 2004. Defense potentials to $\mathrm{NaCl}$ in a mangrove, Bruguiera parviflora: differential changes of isoforms of some antioxidative enzymes. Journal of Plant Physiology 161:531-542.

Pavlovic, A., V. Demko, M. Durchan, and J. Hudák. 2009. Feeding with aminolevulinic acid increased chlorophyll content in Norway spruce (Picea abies) in the dark. Photosynthetica 47:631-634.

Santos, C., H. Azevedo, and G. Caldeira. 2001. In situ and in vitro senescence induced by $\mathrm{KCl}$ stress: nutritional imbalance, lipid peroxidation and antioxidant metabolism. Journal of Experimental Botany 52:351-360.

Wang, R.Z., and Q. Gao. 2003. Climate-driven changes in shoot density and shoot biomass in Leymus chinensis (Poaceae) on the Northeast China Transect (NECT). Global Ecology and Biogeography 12:249-259.

Wang, L.J., W.B. Jiang, H. Liu, W.Q. Liu, L. Kang, and. X.L. Hou. 2005. Promotion by 5-aminolevulinic acid of germination of pakchoi (Brassica campestris) seeds under salt stress. Journal of Integrative Plant Biology 47:1084-1091.

Wang, L.J., X.F. Li, S.Y. Chen, and G.S. Liu . 2009. Enhanced drought tolerance in transgenic Leymus chinensis plants with constitutively expressed wheat TaLEA3. Biotechnology Letters 31:313-319. 
Watanabe, K., T. Tanaka, Y. Hotta, H. Kuramochi, and Y. Takeuchi. 2000. Improving salt tolerance of cotton seedlings with aminolevulinic acid. Plant Growth Regulation 32:99-103.

Wellburn, A.R. 1994. The spectral determination of chlorophyll-a and chlorophhyll-b, as well as total carotenoids, using various solvents with spectrophotometers of different resolution. Journal of Plant Physiology 144:307-313.

Youssef, T., and M.A. Awad. 2008. Mechanisms of enhancing photosynthetic gas exchange in date palm seedlings (Phoenix dactylifera L.) under salinity stress by a 5 -aminolevulinic acidbased fertilizer. Journal of Plant Growth Regulation 27:1-9.

Zhang, J., D.M. Li, Y. Gao, B. Yu, C.X. Xia, and J.G. Bai. 2012. Pretreatment with 5-aminolevulinic acid mitigates heat stress of cucumber leaves. Biologia Plantarum 56:780-784.

Zhang, Z.J., H.Z. Li, W.J. Zhou, Y. Takeuchi, and Y. Yoneyama. 2006. Effect of 5-aminolevulinic acid on development and salt tolerance of potato (Solanum tuberosum L.) microtubers in vitro. Plant Growth Regulation 49:27-34.
Zhang, Q., J.Z. Zhang, W.S. Chow, L.L. Sun, J.W. Chen, Y.J. Chen, et al. 2011. The influence of low temperature on photosynthesis and antioxidant enzymes in sensitive banana and tolerant plantain (Musa sp.) cultivars. Photosynthetica 49:201-208.

Zhang, W.F., F. Zhang, R. Raziuddin, H.J. Gong, Z.M. Yang, L. $\mathrm{Lu}$, et al. 2008. Effects of 5-aminolevulinic acid on oilseed rape seedling growth under herbicide toxicity stress. Journal of Plant Growth Regulation 27:159-169.

Zhen, A., Z.L. Bie, Y. Huang, Z.X. Liu, and M.L. Fan. 2012. Effects of 5-aminolevulinic acid on the $\mathrm{H}_{2} \mathrm{O}_{2}$-content and antioxidative enzyme gene expression in $\mathrm{NaCl}$-treated cucumber seedlings. Biologia Plantarum 56:566-570. 